\title{
Effects of high- and moderate-intensity exercise on central hemodynamic and oxygen uptake recovery kinetics in CHF-COPD overlap
}

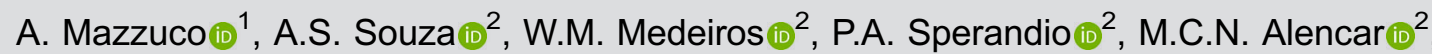 \\ F.F. Arbex (iD) ${ }^{2}$, J.A. Neder (10) ${ }^{3}$, and A. Borghi-Silva (iD) ${ }^{1}$ \\ ${ }^{1}$ Laboratório de Fisioterapia Cardiopulmonar, Departamento de Fisioterapia, Universidade Federal de São Carlos, \\ São Carlos, SP, Brasil \\ ${ }^{2}$ Setor de Função Pulmonar e Fisiologia Clínica do Exercício, Universidade Federal de São Paulo, São Paulo, SP, Brasil \\ ${ }^{3}$ Laboratory of Clinical Exercise Physiology, Division of Respiratory and Critical Care Medicine, Department of Medicine, Queen's \\ University, Kingston, ON, Canada
}

\begin{abstract}
The oxygen uptake $\left(\mathrm{V}_{2}\right)$ kinetics during onset of and recovery from exercise have been shown to provide valuable parameters regarding functional capacity of both chronic obstructive pulmonary disease (COPD) and chronic heart failure (CHF) patients. To investigate the influence of comorbidity of COPD in patients with CHF with reduced ejection fraction on recovery from submaximal exercise, 9 CHF-COPD male patients and 10 age-, gender-, and left ventricle ejection fraction (LVEF)-matched $\mathrm{CHF}$ patients underwent constant-load exercise tests (CLET) at moderate and high loads. The $\mathrm{VO}_{2}$, heart rate (HR), and cardiac output (CO) recovery kinetics were determined for the monoexponential relationship between these variables and time. Within-group analysis showed that the recovery time constant of $\mathrm{HR}(\mathrm{P}<0.05, \mathrm{~d}=1.19$ for CHF and 0.85 for CHF-COPD) and $\mathrm{CO}(\mathrm{P}<0.05, \mathrm{~d}=1.68$ for $\mathrm{CHF}$ and 0.69 for CHF-COPD) and the mean response time (MRT) of $\mathrm{CO}(\mathrm{P}<0.05, \mathrm{~d}=1.84$ for $\mathrm{CHF}$ and 0.73 for CHF-COPD) were slower when moderate and high loads were compared. CHF-COPD patients showed smaller amplitude of $C O$ recovery kinetics $(P<0.05)$ for both moderate $(d=2.15)$ and high $(d=1.07)$ CLET. Although the recovery time constant and MRT means were greater in CHF-COPD, CHF and CHF-COPD groups were not differently affected by load $\left(\mathrm{P}>0.05\right.$ in group vs load analysis). The ventilatory efficiency was related to MRT of $\mathrm{VO}_{2}$ during high CLET $(r=0.71)$. Our results suggested that the combination of CHF and COPD may further impair the recovery kinetics compared to CHF alone.
\end{abstract}

Key words: Chronic heart failure; Chronic obstructive pulmonary disease; Oxygen uptake; Heart rate; Recovery kinetics; Exercise test

\section{Introduction}

Exercise intolerance is a multifactorial hallmark of both chronic heart failure (CHF) (1) and chronic obstructive pulmonary disease (COPD) (2). The consequences of the COPD comorbidity in patients with CHF and vice versa are directly linked to imbalances in the oxygen transport pathways, which encompass perfusion and/or diffusion disorders of the cardiovascular, respiratory, muscular, and cerebral systems, characteristics present in the pathophysiological process of both diseases (3).

The oxygen uptake $\left(\mathrm{VO}_{2}\right)$ kinetics during onset of and recovery from exercise have been shown to provide valuable parameters regarding functional capacity of both COPD and CHF patients, with submaximal exercise being an important assessment ally as far as its metabolic characteristics come closer to activities of daily living $(4,5)$.
Several factors may contribute to the delay in $\mathrm{VO}_{2}$ kinetics during recovery from exercise, including delayed creatine phosphate restoration $(6,7)$, increased arteriovenous oxygen difference due to lower cardiac output (CO) after exercise (6), and slow restoration of venous blood (7) and replenishment of energy stores in peripheral skeletal muscles (8). All these factors, however, are not correlated to markers of disease severity like left ventricular ejection fraction (LVEF) $(6,8)$. Besides, CHF patients with more severe disease, lower exercise capacity, and a flawed ventilation $\left(\dot{V}_{E}\right)$ may be identified by impaired CO kinetics in exercise recovery (9). In addition, the rate of recovery of $\mathrm{VO}_{2}$ at 2 minutes after exercise has been shown to be the strongest prognostic factor of major cardiac events, such as death, heart transplantation,

Correspondence: A. Borghi-Silva: <audrey@ufscar.br>

Received October 8, 2019 | Accepted November 26, 2019 
and mechanical heart implantation in severe $\mathrm{CHF}$ patients (10).

The reduction in systemic oxygen $\left(\mathrm{O}_{2}\right)$ delivery, the higher $\mathrm{O}_{2}$ kinetics during recovery, and the hypoxemia possibly due to hypercapnia in healthy individuals may be explained by the presence of an imposed expiratory flow limitation device during exercise (11). In COPD patients, few studies have explored $\mathrm{VO}_{2}$, heart rate $(\mathrm{HR})$, and $\mathrm{CO}$ from recovery kinetics. A clinical study investigating respiratory gas exchanges and heart rate $(\mathrm{HR})$ kinetics during early-phase recovery after a symptom-limited cardiopulmonary exercise testing (CPET) in COPD patients showed that the quarter-time recovery of $\dot{\mathrm{VO}}_{2}$ increased with disease severity and the kinetics in the early recovery period was slowed compared to the control group (12). Recently, the $\dot{\mathrm{VO}}_{2}$ recovery kinetics (half-time of $\dot{\mathrm{V}} \mathrm{O}_{2}$ recovery $\left(\mathrm{T}_{1 / 2} \dot{\mathrm{V}} \mathrm{O}_{2}\right)$ ) after submaximal exercise has been associated with established parameters of exercise capacity in COPD patients (13). The authors showed that the impairment of the $T_{1 / 2} \quad V_{2}$ also depends on disease severity and degree of airflow limitation, suggesting that prolonged dyspnea or leg effort after exercise, commonly experienced by COPD patients, may be understood by differences in recovery ability.

The calculation of recovery kinetics can be obtained by measuring the time constant (s) of the explored variable $\left(\mathrm{VO}_{2}, \mathrm{HR}\right.$, or $\left.\mathrm{CO}\right)$ by adjusting the curve using a monoexponential equation, where $63 \%$ of the time to achieve stabilization of the variable of interest, adjusted by its maximum value in the steady-state exercise (9), represented the $\tau(\mathrm{s})$. In addition, the mean response time (MRT) is defined as the sum of the exponential time constant of decay plus a delay term, from end-exercise to the onset of exponential decay (11). Both variables express important diagnostic and prognostic markers to assess the physiological mechanisms underlying exercise intolerance and the impact of COPD on CHF patients.

In this context, previous studies have shown that $\dot{\mathrm{VO}}_{2}$ and $H R$ recovery kinetics are slowed in the presence of COPD (12-13) or CHF (8-10) on isolation, as represented by $\tau$ and MRT. However, to the best of our knowledge, the recovery kinetics in patients with overlapped $\mathrm{CHF}$ and COPD has not been thoroughly explored. Moreover, it is not known whether the kinetics of $\dot{\mathrm{VO}}_{2}, \mathrm{HR}$, and $\mathrm{CO}$ recovery are also intensity-dependent, contrasting the presence of COPD in CHF patients.

Therefore, the main objective of this study was to investigate the influence of comorbidity of COPD in patients with $\mathrm{CHF}$ with reduced ejection fraction on $\dot{\mathrm{VO}}_{2}$, $\mathrm{HR}$, and CO recovery kinetics after moderate and high constant-load exercise test (CLET). Considering that the combination of these two chronic diseases may potentiate the abnormalities observed in each case individually, we hypothesized that the cardiovascular (represented by the slower response of $\tau$ and MRT) and the respiratory interaction (represented by the association with ventilatory efficiency indices) in patients with the coexistence of CHF and COPD may further impair recovery from submaximal intensity exercise (moderate and high), consequently slowing the recovery kinetics to a greater extent compared to patients with CHF alone.

\section{Material and Methods}

\section{Subjects}

Nine sedentary males with a smoking-related spirometric diagnosis of COPD (forced expiratory volume in $1 \mathrm{~s}\left(\mathrm{FEV}_{1}\right) /$ forced vital capacity $\left.(\mathrm{FVC})<0.7\right)(14)$, resting arterial oxygen tension $\geqslant 60 \mathrm{~mm} \mathrm{Hg}$ at room air, and echocardiographic evidence of heart failure with reduced LVEF $<40 \%$ and 10 age-, gender-, and LVEF-matched CHF patients were enrolled in this prospective, crosssectional clinical study. All patients were seen by the same cardiologists and pulmonologists at an outpatient specialized clinic and optimally treated before study initiation for at least 3 months (Table 1).

No decompensation episodes occurred in any enrolled subject for at least one month prior to study initiation. Main exclusion criteria were long-term $\mathrm{O}_{2}$ therapy (for at least 6 months), recent (within 6 months) rehabilitation, type I or non-controlled type II diabetes mellitus, and peripheral vascular disease, orthopedic/rheumatological/neurological conditions that would preclude participation in the study, other concomitant respiratory diseases, any contraindication to exercise testing according to the American Heart Association guidelines (15), and inability to understand and cooperate with the procedures. All subjects were informed about study objectives, experimental procedures, and potential risks and gave written informed consent before study initiation. The study was approved by the Medical Ethics Committee of São Paulo Hospital, Brazil (protocol 424.135/2013) and Ethics Committee on Human Research at the Federal University of São Carlos (UFSCar), Brazil (protocol 515.654 /2014).

\section{Experimental design}

All patients underwent a comprehensive evaluation divided into three different days with intervals of one week between them. On day 1, patients underwent a clinical evaluation by a physician and a physical therapist, followed by lung function tests and Doppler echocardiography. On the second day, patients underwent a CPET. After $48 \mathrm{~h}$, patients were invited to conclude 2 CLETs with intervals of $30 \mathrm{~min}$ between them. Moderate intensity CLET (40-50\% of maximal) was applied first and after a rest period of $4 \mathrm{~min}$, high intensity CLET (70-80\% of maximal) was applied. The order used is based on previous studies that consider that moderate intensity (40-50\% of peak workload) does not affect subsequent intensity $(16,17)$. 
Table 1. Baseline demographic and clinical characteristics data of patients with chronic heart failure (CHF) and CHF-chronic obstructive pulmonary disease (COPD).

\begin{tabular}{|c|c|c|}
\hline & CHF $(n=10)$ & CHF-COPD $(n=9)$ \\
\hline \multicolumn{3}{|l|}{ Demographics } \\
\hline Age, years & $61.1 \pm 6.7$ & $66.2 \pm 5.9$ \\
\hline BMl, $\mathrm{kg} / \mathrm{m}^{2}$ & $26.2 \pm 3.3$ & $24.8 \pm 2.9$ \\
\hline $\mathrm{mMRC} \geqslant 2, \%$ & 0.7 & 0.3 \\
\hline NYHA score II-III, \% & 0.8 & 0.7 \\
\hline Smoking, never/ex/current, n (\%) & $0 / 9(0.9) / 1(0.1)$ & $0 / 9(1.0) / 0$ \\
\hline pack-years & $49.4 \pm 26.2$ & $53.9 \pm 35.5$ \\
\hline \multicolumn{3}{|l|}{ Echocardiogram } \\
\hline LVEF, \% & $31.0 \pm 4.6$ & $34.4 \pm 6.6$ \\
\hline \multicolumn{3}{|l|}{ Lung function } \\
\hline FVC, \% pred & $82.8 \pm 11.4$ & $79.9 \pm 11.3$ \\
\hline FVC, L & $3.3 \pm 0.5$ & $3.0 \pm 0.5$ \\
\hline $\mathrm{FEV}_{1}, \%$ pred & $82.7 \pm 12.1$ & $65.7 \pm 15.3^{*}$ \\
\hline $\mathrm{FEV}_{1}, \mathrm{~L}$ & $2.5 \pm 0.4$ & $1.9 \pm 0.5^{\star}$ \\
\hline $\mathrm{FEV}_{1} / \mathrm{FVC}$ & $77.8 \pm 3.7$ & $62.5 \pm 10.0^{* *}$ \\
\hline $\mathrm{PaO}_{2}, \mathrm{mmHg}$ & $84.5 \pm 10.5$ & $75.7 \pm 7.6$ \\
\hline $\mathrm{PaCO}_{2}, \mathrm{mmHg}$ & $32.8 \pm 3.5$ & $35.3 \pm 1.9$ \\
\hline $\mathrm{SpO}_{2}, \%$ & $95.5 \pm 2.3$ & $94.9 \pm 1.8$ \\
\hline \multicolumn{3}{|l|}{ Main co-morbidities, n (\%) } \\
\hline Hypertension & $9(90)$ & $8(88.9)$ \\
\hline Type II diabetes & $6(60)$ & $2(22.2)$ \\
\hline Hypercholesterolemia & $6(60)$ & $6(66.7)$ \\
\hline Sleep apnea & $3(30)$ & $1(11.1)$ \\
\hline Chronic kidney disease & 0 & $3(33.3)$ \\
\hline Chronic atrial fibrillation & $1(10)$ & $1(11.1)$ \\
\hline CAD & $4(40)$ & $2(22.2)$ \\
\hline Alcoholism, ex/current & $3(30) / 0$ & $2(22.2) / 0$ \\
\hline \multicolumn{3}{|l|}{ Therapies, $\mathrm{n}(\%)$} \\
\hline LABA & 0 & $4(44.4)^{*}$ \\
\hline LAMA & 0 & $2(22.2)$ \\
\hline ICS & 0 & $1(11.1)$ \\
\hline Xanthines & 0 & $1(11.1)$ \\
\hline LABA + LAMA & 0 & $3(33.3)$ \\
\hline $\mathrm{LABA}+\mathrm{ICS}$ & 0 & $2(22.2)$ \\
\hline LABA + ICS + LAMA & 0 & 0 \\
\hline Beta-blockers & $10(100)$ & $9(100)$ \\
\hline ACE inhibitors/ARB II & $10(100)$ & $8(88.9)$ \\
\hline Calcium channel blocker & 0 & $3(33.3)$ \\
\hline Diuretics & $10(100)$ & $9(100)$ \\
\hline Digitalis & $4(40)$ & $4(44.4)$ \\
\hline Platelet antiaggregants & $5(50)$ & $6(66.7)$ \\
\hline Statins & $7(70)$ & $6(66.7)$ \\
\hline Antiarrhythmics & $1(10)$ & $1(11.1)$ \\
\hline Hypoglycemics & $6(60)$ & $2(22.2)$ \\
\hline Gastric protection drugs & $5(50)$ & $3(33.3)$ \\
\hline
\end{tabular}

BMI: body mass index; mMRC: modified Medical Research Council; NYHA: New York Heart Association; LVEF: left ventricular ejection fraction; FVC: forced vital capacity; $\mathrm{FEV}_{1}$ : forced expiratory volume in $1 \mathrm{~s}$; $\mathrm{PaO}_{2}$ : partial pressure for $\mathrm{O}_{2} ; \mathrm{PaCO}_{2}$ : partial pressure for $\mathrm{CO}_{2} ; \mathrm{SpO}_{2}$ : peripheral oxygen saturation; CAD: coronary arterial disease; LABA: long-acting beta ${ }_{2}$-agonist; LAMA: long-acting anticholinergics; ICS: inhaled corticosteroids; ACE inhibitors: angiotensin-converting-enzyme inhibitors; ARB II: angiotensin II receptor blockers. LVSD-n=9 for CHF and 6 for CHF-COPD; LAV-n=9 for CHF and 6 for CHF-COPD; $\mathrm{n}$ patients were able to achieve acceptable test criteria for $\mathrm{DL}_{\mathrm{CO}}=9$ for $\mathrm{CHF}$ and 7 for CHF-COPD. Data are reported as means $\pm S D$ or $n$ (percentage). ${ }^{*} \mathrm{P}<0.05$; ${ }^{* *} \mathrm{P}<0.001$ (Student's $t$-test). 


\section{Day 1}

Lung function. Spirometry (1085 ELITE DTM, Medical Graphics Corporation, USA) was measured according to American Thoracic Society/European Respiratory Society guidelines (18). Resting blood gases were obtained by samples from the radial artery (19).

Doppler echocardiography. Echocardiography was performed by the same trained echocardiographist (20) and the left ventricular ejection fraction (\%) was determined.

Clinical and physical therapy evaluation. Patients were evaluated by a clinician to assess disease stability and check the use of all mediations and general condition. An experienced physical therapist evaluated the patients' functional capacity by a report of physical limitation and applied a physical exam in order to evaluate musculoskeletal disorders that could interfere with the tests to be applied.

\section{Day 2: maximal exercise testing to determine submaximal loads}

Cardiopulmonary exercise testing. Patients performed a symptom-limited, ramp incremental exercise test $(5$ or $10 \mathrm{~W}$ ) on an electronically braked cycle ergometer (Corival 400, Lode BV, Netherlands). $\mathrm{VO}_{2}(\mathrm{~mL} / \mathrm{min})$, carbon dioxide output $\left(\dot{\mathrm{V}} \mathrm{CO}_{2} ; \mathrm{mL} / \mathrm{min}\right)$, minute ventilation $\left(\dot{\mathrm{V}}_{\mathrm{E}} ; \mathrm{L} / \mathrm{min}\right)$, endtidal partial pressures for $\mathrm{O}_{2}$ and $\mathrm{CO}_{2}$, respiratory exchange ratio (RER $=\dot{\mathrm{V}} \mathrm{CO}_{2} / \mathrm{NO}_{2}$ ), tidal volume $(\mathrm{VT}, \mathrm{mL}$ ), and respiratory frequency (breaths/min) were measured breath by breath using a computer-based system (CardiO2 System, Medical Graphics). All ventilatory and cardiocirculatory variables of gas exchange were averaged every $15 \mathrm{~s}$, and $\mathrm{VO}_{2}$ peak was defined as the highest value achieved during the test (21). HR (beats/min) was determined using the R-R intervals from a 12-lead electrocardiogram and continuously monitored potential cardiac arrhythmias. Peripheral oxygen saturation was determined by pulse oximetry $\left(\mathrm{SpO}_{2}\right.$ in \%; POX 010-340, Mediaid, USA]. Patients were also asked to rate their "shortness of breath" at exercise cessation using the $0-10$ Borg's category ratio scale (22). In addition, using CPET data, the $\dot{\mathrm{V}}_{\mathrm{E}} / \mathrm{VCO}_{2}$ relationship from the beginning of exercise to peak exercise was derived by least squares linear regression (i.e., $y=x+b, m=$ slope) (Microsoft Excel, Microsoft Corp., USA). The oxygen uptake efficiency slope (OUES) was calculated using the log-transformation (base 10) of $\dot{V}_{E}(L / m i n)$ on the $x$-axis and $\dot{\mathrm{VO}}_{2}(\mathrm{~L} / \mathrm{min})$ on the $\mathrm{y}$-axis (23). Circulatory power ( $\mathrm{mmHg} \cdot \mathrm{mL} \mathrm{O} \mathrm{O}_{2} / \mathrm{kg} / \mathrm{min}$ ) was defined as the product of peak $\dot{\mathrm{V}}_{2}$ and peak SBP (24). Exercise ventilatory power $(\mathrm{mmHg})$ was defined as peak SBP divided by the $\dot{V}_{E} /$ $\dot{\mathrm{V}} \mathrm{CO}_{2}$ slope (25). Heart rate (bpm) was determined using the RR interval from the Polar ${ }^{\mathbb{R}}$ system (Polar ${ }^{\mathbb{R}}$ S810i, Finland).

\section{Day 3: experimental protocol}

One week after CPET, patients performed a two-stage cycle ergometer test starting at 40 to $50 \%$ during $4 \mathrm{~min}$ of exercise and a 4-min passive resting period. After this period, a second intensity was applied at $70-80 \%$ of the peak work rate achieved on CPET (high) during 4 min or until the limit of tolerance. All ventilatory, cardiocirculatory, and metabolic variables were also obtained.

Cardiac output. Hemodynamic variables (stroke volume: SV (mL), HR (bpm), and CO (L/min)) were noninvasively assessed throughout the CLET by a calibrated signal-morphology impedance cardiography system (PhysioflowPF-5 ${ }^{\mathrm{TM}}$, Manatec Biomedical, France). Principles of operation and algorithms have been previously described (26).

Kinetics analysis. The breath-by-breath $\mathrm{V}_{2}, \mathrm{HR}$, and hemodynamic $\mathrm{CO}$ data were time-aligned to $30 \mathrm{~s}$ of the end of exercise bouts and interpolated second by second. The kinetics of these responses were determined by nonlinear regression using a least squares technique and the exponential time constant $\tau$ of $\dot{\mathrm{VO}}_{2}, \mathrm{HR}$, and $\mathrm{CO}$ decay in recovery was determined for the monoexponential relationship (4) between these variables and time during $240 \mathrm{~s}$ of recovery using the following formula (SigmaPlot 11.0, Systat Software Inc., USA): $Y=Y O-A *\left(1-e^{-(t-T d) / \tau}\right)$, where $\mathrm{Y}$ is the $\dot{\mathrm{VO}} \mathrm{O}_{2}, \mathrm{HR}$, or $\mathrm{CO}, \mathrm{YO}$ is $\dot{\mathrm{VO}}{ }_{2}, \mathrm{HR}$, or $\mathrm{CO}$ at time zero (beginning of the recovery phase), $\mathrm{A}$ is $\mathrm{VO}_{2}, \mathrm{HR}$, or $\mathrm{CO}$ amplitude during exercise recovery $\left(\mathrm{mL} \cdot \mathrm{kg}^{-1} \cdot \mathrm{min}^{-1}\right.$, bpm, L/min, respectively), Td is the time delay (s), and $\tau$ is the exponential time constant (s). This time constant reflects the time required to achieve $63 \%$ of the difference between starting and baseline values. The overall kinetics was determined by the mean response time (MRT $=\tau+T d$ ). Fit quality was determined by the sum of the squared residuals and by the coefficient of determination $R^{2}$.

\section{Statistical analysis}

Results are reported as means \pm SD unless otherwise stated. All statistical analyses were conducted at a $95 \%$ level of significance using SPSS Statistics for Windows software package, Version 17.0 (IBM, USA). After visual inspections, the Shapiro-Wilk test was used to verify the normality of data and the Levene's test was used to check homogeneity of data. For baseline patient characteristics and responses of CPET, CHF and CHF-COPD patients were contrasted by independent $t$-tests or Mann-Whitney test, according to variable distribution. Fisher's exact test was used for categorical data comparisons. Two-way analysis of variance (ANOVA) for repeated measures was performed contrasting intensities as within-subjects variable (moderate and high) and groups (CHF and CHF-COPD) as between-subjects factor to compare peak cardiopulmonary, metabolic, hemodynamic, and recovery kinetics responses with Bonferroni's post hoc test. For respective post hoc observations, we determined Cohen's d effect size for the differences between groups and intensities and interpreted as small (0.20-0.49), medium $(0.50-0.79)$, large $(0.80-1.29)$, and very large (>1.30) (27). 
Pearson's correlation coefficients were used to test the association between $\tau$ and MRT of $\mathrm{VO}_{2}, \mathrm{HR}$, and $\mathrm{CO}$ (dependent variables) and markers of disease severity at rest (LVEF and $V F_{1}$ ) and during maximal exercise (peak $\dot{\mathrm{V}} \mathrm{O}_{2}$, peak $\mathrm{HR}, \mathrm{HR}$ recovery at 1 min post-CPET-HRR ${ }_{1}$, $\Delta \dot{V}_{2} / \Delta$ work rate (WR), OUES, and $\dot{\mathrm{V}}_{\mathrm{E}} / \dot{\mathrm{V}} \mathrm{CO}_{2}$ slope) (independent variables). The magnitude of correlations was determined considering the following classification scheme for $r$ values: $0.26-0.49$ : low or weak; $0.50-0.69$ : moderate; $0.70-0.89$ : strong or high; 0.90-1.0: very high (28).

\section{Results}

\section{General characteristics}

Figure 1 shows the flowchart of the study. A total of 39 patients (19 with CHF and 20 with CHF-COPD) were recruited from a specialized outpatient CHF/CHF-COPD clinic (convenience sample). Seventeen did not fulfill inclusion criteria [clinical decompensation (1 CHF, 3 CHF-COPD), high physical activity level (1 CHF), orthopedic limitation (1 CHF, 1 CHF-COPD), BMI above 30 (1 CHF-COPD), pulmonary fibrosis (1 CHF-COPD), and refusal to participate (5 CHF, $3 \mathrm{CHF}-\mathrm{COPD})]$. Eleven patients with $\mathrm{CHF}$ and 11 with $\mathrm{CHF}-\mathrm{COPD}$ were initially included, however 3 were excluded [did not perform CPET adequately (1 CHF) and cardiorespiratory events (2 CHFCOPD, 1 respiratory arrest and 1 sustained ventricular tachycardia both during CLET)].

Baseline demographic and clinical characteristics are shown in Table 1. Subjects were matched for age, BMI, symptoms, and LVEF. As expected, CHF-COPD patients presented with lower $\mathrm{FEV}_{1}$ and higher long-acting beta ${ }_{2}^{-}$ agonist use, however, with non-significant differences in arterial oxygenation and $\mathrm{PaCO}_{2}$. The most common cause of CHF was ischemic cardiomyopathy (9 CHF, 5 CHF-COPD), followed by idiopathic etiology (1 CHF, 3 CHF-COPD) and valvular etiology (1 CHF-COPD).

Table 2 shows the comparisons of the cardiopulmonary exercise testing between the groups. The groups presented similar reduced workload on peak and when compared to the predicted values. In addition, groups were similar in relation to all cardiorespiratory and metabolic parameters, and limiting symptom at peak exercise. In both groups, predicted HR were reduced and the groups used beta blockers in similar percentages (see Table 1).

\section{$\mathrm{HR}, \mathrm{VO}_{2}$, and $\mathrm{CO}$ off-kinetics responses to moderate and high CLET}

The cardiovascular, ventilatory, and hemodynamic responses to moderate and high intensities CLET are shown in Table 3. In the present study, as expected, in both groups, high intensities led to higher $\dot{\mathrm{V}} \mathrm{O}_{2}, \dot{\mathrm{V}} \mathrm{CO}_{2}, \mathrm{HR}$, $\mathrm{VE}$, and $\mathrm{CO}(\mathrm{P}<0.05)$. However, peak $\mathrm{HR}$ and $\mathrm{CO}$ were lower in CHF-COPD group compared with $\mathrm{CHF}$ alone when high intensities were applied $(P<0.05)$. There was no interaction between the groups when the two intensities were contrasted $(P>0.05)$.

The $\mathrm{HR}, \dot{\mathrm{VO}} 2$, and $\mathrm{CO}$ off-kinetics variables at moderate and high exercise intensities in both groups are reported in Supplementary Table S1. There was a significant main effect of intensity on the baseline (YO) and A of $\mathrm{HR}, \dot{\mathrm{V}} \mathrm{O}_{2}$, and $\mathrm{CO}$ in both groups $(\mathrm{P}<0.05)$. However, $\mathrm{A}$ of $\mathrm{CO}$ was lower in CHF-COPD compared with $\mathrm{CHF}$, both at moderate and high intensities $(P<0.05)$.

Regarding the effects of moderate and high CLET on the exponential time constant $\tau$, there was a significant

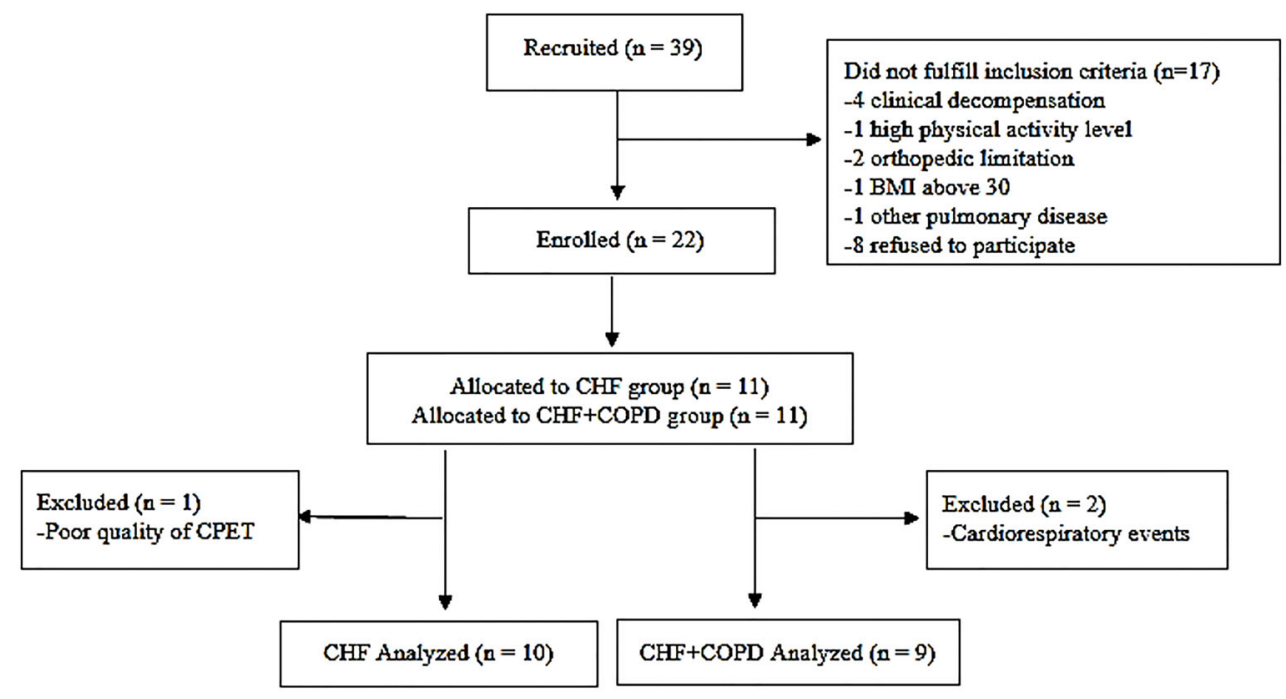

Figure 1. Flowchart of the study. COPD: chronic obstructive pulmonary disease; CHF: chronic heart failure. 
Table 2. Comparison of cardiorespiratory and metabolic responses obtained at peak of cardiopulmonary exercise testing between chronic heart failure $(\mathrm{CHF})$ and CHF-chronic obstructive pulmonary disease (COPD) patients.

\begin{tabular}{|c|c|c|}
\hline & $\mathrm{CHF}(n=10)$ & CHF-COPD $(n=9)$ \\
\hline Peak WR, W & $71.7 \pm 29.7$ & $58.9 \pm 14.2$ \\
\hline Peak WR, \% pred & $57.1 \pm 19.5$ & $53.4 \pm 11.1$ \\
\hline Peak $\dot{\mathrm{V}} \mathrm{O}_{2}, \mathrm{~mL} \cdot \mathrm{kg}^{-1} \cdot \mathrm{min}^{-1}$ & $15.5 \pm 5.0$ & $14.7 \pm 2.4$ \\
\hline Peak $\dot{\mathrm{VO}}_{2}, \%$ pred & $63.5 \pm 18.2$ & $63.6 \pm 7.7$ \\
\hline Rest $\mathrm{P}_{\mathrm{ET}} \mathrm{CO}_{2}, \mathrm{mmHg}$ & $31.2 \pm 2.6$ & $30.6 \pm 3.3$ \\
\hline Peak $\mathrm{P}_{\mathrm{ET}} \mathrm{CO}_{2}, \mathrm{mmHg}$ & $30.7[23.8-34.7]$ & $31.6[28.7-32.4]$ \\
\hline Peak RER & $1.2[1.1-1.3]$ & $1.1[1.0-1.2]$ \\
\hline Peak HR, bpm & $118.6 \pm 20.1$ & $101.7 \pm 21.3$ \\
\hline Peak HR, \% pred & $74.5 \pm 12.3$ & $66.0 \pm 13.2$ \\
\hline Peak SBP, mmHg & $118.9 \pm 23.9$ & $124.7 \pm 17.9$ \\
\hline Peak DBP, mmHg & $70.8 \pm 11.3$ & $71.7 \pm 13.0$ \\
\hline Peak $\mathrm{O}_{2}$ pulse, $\mathrm{mL} \cdot$ beat $^{-1}$ & $10.0 \pm 3.4$ & $10.4 \pm 2.3$ \\
\hline Peak $\mathrm{SpO}_{2}, \%$ & $97.0 \pm 1.6$ & $94.9 \pm 3.6$ \\
\hline Peak-rest $\mathrm{SpO}_{2}, \%$ & $1.0[(-1.0)-1.0]$ & $0.0[(-1.0)-0.5]$ \\
\hline Peak Borg dyspnea score & $7.2 \pm 2.5$ & $7.8 \pm 1.6$ \\
\hline Peak Borg fatigue score & $8.5[6.3-10.0]$ & $10.0[7.5-10.0]$ \\
\hline $\mathrm{HRR}^{1}, \mathrm{bpm}$ & $18.8 \pm 11.9$ & $10.7 \pm 7.2$ \\
\hline$\Delta \dot{\mathrm{VO}}_{2} / \Delta \mathrm{WR}, \mathrm{mL} \cdot \mathrm{min}^{-1} \cdot \mathrm{W}^{-1}$ & $9.3 \pm 2.9$ & $8.6 \pm 1.9$ \\
\hline$\dot{\mathrm{V}}_{\mathrm{E}} / \dot{\mathrm{V}} \mathrm{CO}_{2}$ slope & $39.5 \pm 10.4$ & $37.0 \pm 6.2$ \\
\hline OUES & $1.4 \pm 0.5$ & $1.4 \pm 0.3$ \\
\hline $\mathrm{CP}, \mathrm{mmHg} \cdot \mathrm{mlO}_{2} \cdot \mathrm{kg}^{-1} \cdot \mathrm{min}^{-1}$ & $1876.7 \pm 790.8$ & $1830.1 \pm 383.0$ \\
\hline EVP, mmHg & $3.3 \pm 1.2$ & $3.4 \pm 0.5$ \\
\hline
\end{tabular}

WR: work rate; $\dot{\mathrm{VO}}_{2}$ : oxygen uptake; $\mathrm{P}_{\mathrm{ET}} \mathrm{CO}_{2}$ : end-tidal partial pressure for $\mathrm{CO}_{2}$; RER: respiratory exchange ratio; HR: heart rate; SBP: systolic blood pressure; DBP: diastolic blood pressure; $\mathrm{SpO}_{2}$ : pulse oximetry; $\mathrm{HRR}_{1}$ : heart rate recovery at $1 \mathrm{~min} ; \dot{\mathrm{V}}_{\mathrm{E}}$ : ventilation; OUES: slope efficiency uptake oxygen; $\mathrm{CP}$ : circulatory power; EVP: exercise ventilatory power. Data are reported as mean \pm SD or median [interquartile range]. No difference was observed between groups (Student's $t$-test).

Table 3. Peak responses to moderate and high intensities during constant workload exercise testing in chronic heart failure (CHF) and CHF-chronic obstructive pulmonary disease (COPD) groups.

\begin{tabular}{|c|c|c|c|c|c|c|c|}
\hline & \multicolumn{2}{|c|}{ Moderate } & \multicolumn{2}{|c|}{ High } & \multirow{2}{*}{$\frac{\text { Group }}{P}$} & \multirow{2}{*}{$\frac{\text { Intensity }}{\mathrm{P}}$} & \multirow{2}{*}{$\frac{\text { Interaction }}{\mathrm{P}}$} \\
\hline & $\mathrm{CHF}$ & CHF-COPD & $\mathrm{CHF}$ & CHF-COPD & & & \\
\hline$\dot{\mathrm{V}} \mathrm{O}_{2}, \mathrm{~mL} \cdot \mathrm{kg}^{-1} \cdot \mathrm{min}^{-1}$ & $10.2 \pm 2.6$ & $9.8 \pm 1.3$ & $13.4 \pm 3.8$ & $13.0 \pm 3.0$ & 0.69 & 0.004 & 0.99 \\
\hline$\dot{\mathrm{V}} \mathrm{CO}_{2}, \mathrm{~mL} \cdot \mathrm{min}^{-1}$ & $685.7 \pm 191.3$ & $606.3 \pm 105.2$ & $976.8 \pm 256.9$ & $845.1 \pm 190.5$ & 0.06 & $<0.001$ & 0.92 \\
\hline $\mathrm{P}_{\mathrm{ET}} \mathrm{CO}_{2}, \mathrm{mmHg}$ & $27.5 \pm 3.3$ & $27.6 \pm 3.0$ & $24.9 \pm 3.6$ & $25.3 \pm 3.6$ & 0.76 & 0.12 & 0.98 \\
\hline $\mathrm{P}_{\mathrm{ET}} \mathrm{O}_{2}, \mathrm{mmHg}$ & $115.7 \pm 5.8$ & $113.6 \pm 8.0$ & $120.7 \pm 6.0$ & $117.6 \pm 10.0$ & 0.18 & 0.16 & 0.97 \\
\hline $\mathrm{HR}$, bpm & $92.7 \pm 12.4$ & $89.4 \pm 14.6$ & $115.3 \pm 27.3$ & $97.3 \pm 18.1$ & 0.01 & 0.03 & 0.39 \\
\hline $\mathrm{SBP}, \mathrm{mmHg}$ & $115.2 \pm 21.0$ & $115.4 \pm 10.3$ & $125.2 \pm 25.4$ & $130.2 \pm 17.8$ & 0.68 & 0.06 & 0.71 \\
\hline $\mathrm{DBP}, \mathrm{mmHg}$ & $74.6 \pm 16.7$ & $66.7 \pm 12.0$ & $74.6 \pm 16.4$ & $70.7 \pm 15.3$ & 0.24 & 0.69 & 0.68 \\
\hline$\dot{\mathrm{V}}_{\mathrm{E}}, \mathrm{L}$ & $30.0 \pm 6.2$ & $27.7 \pm 5.4$ & $46.8 \pm 9.1$ & $41.3 \pm 11.2$ & 0.11 & $<0.001$ & 0.85 \\
\hline $\mathrm{SV}, \mathrm{mL}$ & $72.9 \pm 11.8$ & $77.2 \pm 20.9$ & $80.4 \pm 15.3$ & $75.3 \pm 21.8$ & 0.69 & 0.86 & 0.66 \\
\hline $\mathrm{CO}, \mathrm{L} \cdot \mathrm{min}^{-1}$ & $6.6 \pm 1.5$ & $6.2 \pm 2.2$ & $9.1 \pm 1.9$ & $7.5 \pm 2.5$ & 0.02 & 0.01 & 0.57 \\
\hline $\mathrm{HRR}_{1}, \mathrm{bpm}$ & $15.0 \pm 6.0$ & $13.3 \pm 9.4$ & $18.9 \pm 11.3$ & $15.4 \pm 10.7$ & 0.41 & 0.33 & 0.77 \\
\hline
\end{tabular}

$\dot{\mathrm{V}} \mathrm{O}_{2}$ : oxygen uptake; $\dot{\mathrm{V} C \mathrm{CO}_{2}}$ : carbon dioxide output; $\mathrm{P}_{\mathrm{ET}} \mathrm{CO}_{2}$ : end-tidal partial pressure for $\mathrm{CO}_{2} ; \mathrm{P}_{\mathrm{ET}} \mathrm{O}_{2}$ : end-tidal partial pressure for $\mathrm{O}_{2}$; HR: heart rate; SBP: systolic blood pressure; DBP: diastolic blood pressure; $\dot{\mathrm{V}}_{\mathrm{E}}$ ventilation; SV: stroke volume; CO: cardiac output; $H R R_{1}$ : heart rate recovery in the first minute. Data are reported as mean \pm SD (ANOVA). 
main effect of intensity on $\mathrm{HR}$ and $\mathrm{CO}$ recovery kinetics $(P<0.05)$. However, there was a non-significant main effect of group on the $\tau$ of these variables. Only the MRT of CO was significantly affected by intensity in both groups $(P<0.05)$. Nevertheless, there was a non-significant interaction between groups versus intensities (Table 3 and Figure 2).

As shown in Figure 3 , the $\dot{\mathrm{V}}_{\mathrm{E}} / \mathrm{V}_{\mathrm{CO}}$ slope was significantly related to MRT of $\dot{\mathrm{V}} \mathrm{O}_{2}$ during recovery from high CLET in CHF-COPD patients but not in CHF.

\section{Discussion}

This is the first cross-sectional study to investigate the influence of comorbidity of COPD in patients with $\mathrm{CHF}$ with reduced LVEF on recovery kinetics after moderate and high CLET. Our preliminary analysis showed that the amplitude of $\mathrm{HR}, \mathrm{VO}_{2}$, and $\mathrm{CO}$ were higher at high intensities, regardless of the presence or absence of COPD in CHF. In addition, $\tau$ of HR and CO, and MRT of $\mathrm{CO}$ were slowed down at high intensities, regardless of the presence or absence of COPD in CHF. However, the amplitude of $\mathrm{CO}$ was significantly lower in patients with COPD coexistence in CHF compared with CHF alone, at both moderate and high exercise intensity $(P<0.05)$.
Altogether, the recovery kinetics analysis after submaximal exercise (moderate and high loads) might be useful to assess metabolic characteristics that can clinically reflect prolonged dyspnea and leg effort experienced during activities of daily living of CHF and particularly of CHFCOPD patients. Additionally, the assessment of recovery profile of CHF with comorbidity of COPD might also be helpful to determine the effects of exercise interventions such as interval exercise training.

We expected that recovery kinetics after high intensity exercise was statistically greater compared to moderate when within-group contrasts were considered (represented by $\tau$ of HR and CO, and MRT of CO). In COPD patients, the off-MRT response of $\mathrm{CO}$ was independent of exercise modality, which was attributed to the fact that cycling (at $75 \%$ of workload) at moderate intensities and 6-min walking test are submaximal intensities and are maintained at a constant rate of physical effort (29). The two exercise bouts performed in the present study (40$50 \%$ and $70-80 \%$ of workload), although characteristically submaximal, differed in terms of baseline (Y0) and $A$ of $\mathrm{HR}, \mathrm{VO}_{2}$, and $\mathrm{CO}$ in both groups. Indeed, we observed that differences were more evident in $\mathrm{CHF}$ patients, mainly because SV, HR, and consequently $\mathrm{CO}$ responses to high-load exercise were attenuated in CHF-COPD
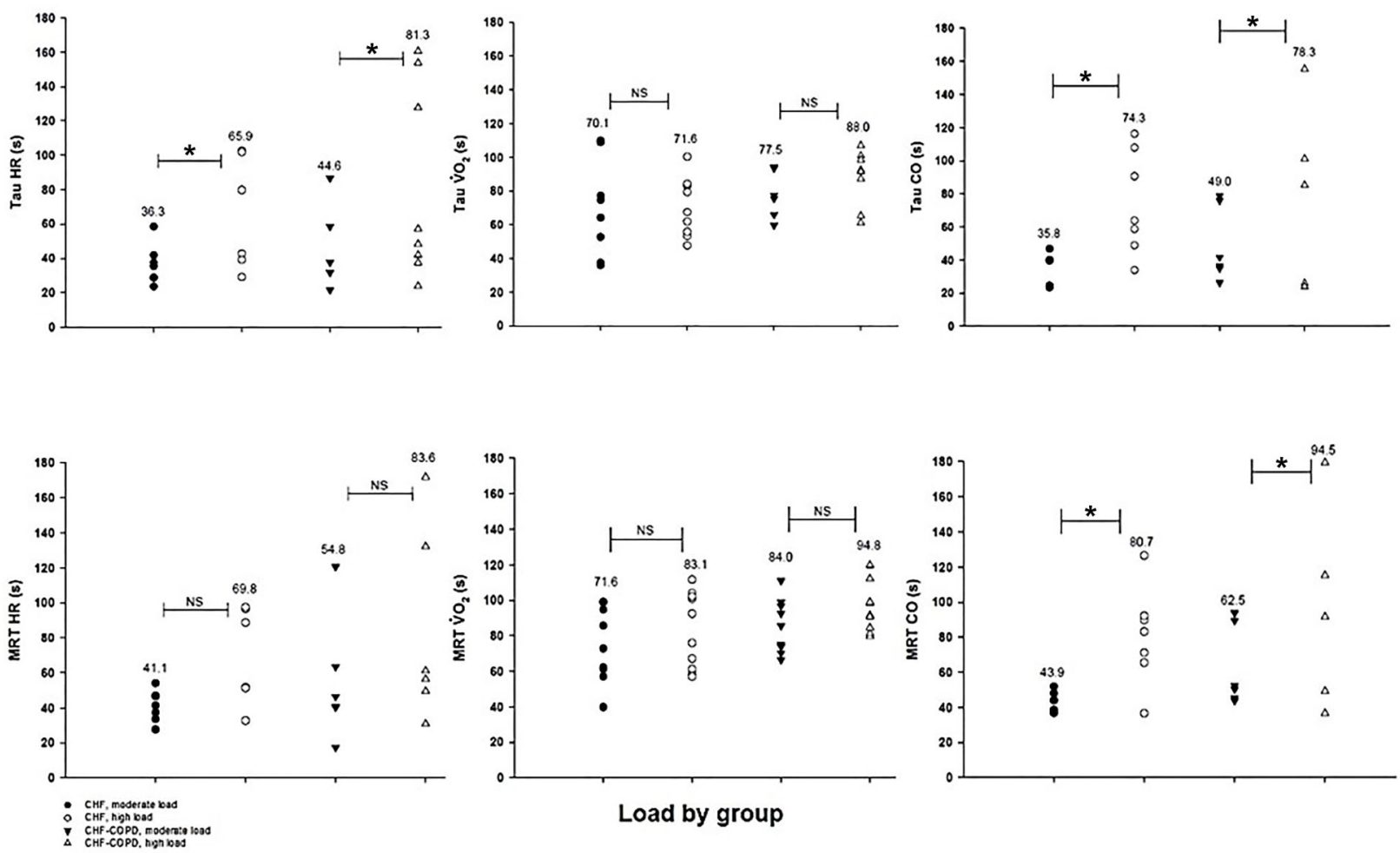

Figure 2. Heart rate $(\mathrm{HR})$, oxygen uptake $\left(\mathrm{V}_{2}\right)$, and cardiac output $(\mathrm{CO})$ off-kinetics variables at moderate and high constant-load exercise test in chronic heart failure (CHF) and CHF-chronic obstructive pulmonary disease (COPD) groups. MRT: mean response time; Tau: time constant; NS: not significant. * $\mathrm{P}<0.05$ (ANOVA) ( $n=6-8$ per group). 


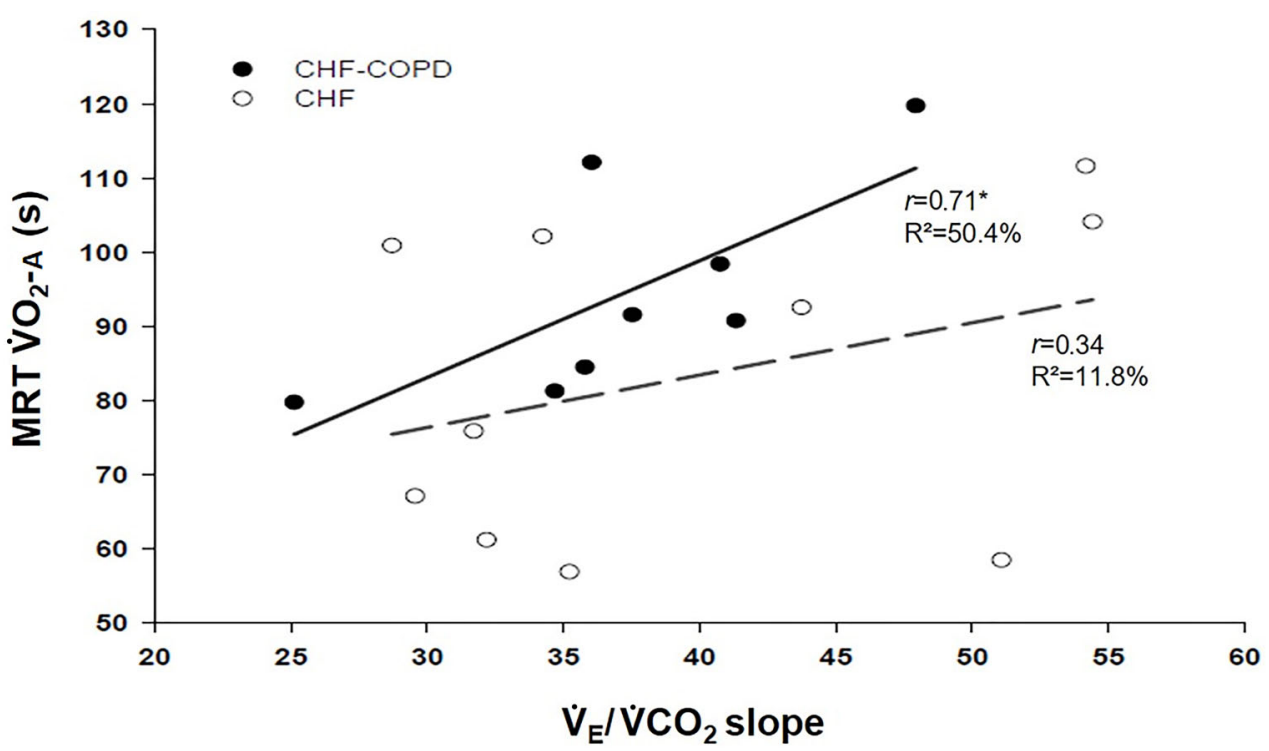

Figure 3. Relationship between ventilation/carbon dioxide output $\left(\dot{V}{ }_{E} / \dot{V} \mathrm{CO}_{2}\right)$ slope and mean response time (MRT) of oxygen uptake $\left(\mathrm{V}_{2}\right)$ during high constant-load exercise test in patients with chronic heart failure (CHF) and CHF-chronic obstructive pulmonary disease (COPD). ${ }^{*} \mathrm{P}<0.05$.

patients (Table 3 ). In fact, it has been shown that effortindependent variables like OUES and $\tau$ of $\mathrm{VO}_{2}$ kinetics during recovery from submaximal constant-load exercise are clinically useful for detecting training effects in $\mathrm{CHF}$ patients (12-week combined cycle interval and muscle resistance training program) (30). In CHF patients who underwent a 12-week high-intensity interval training $(4 \times$ $4 \mathrm{~min}$ at $85-95 \%$ of peak $\dot{\mathrm{VO}}_{2}$ ), the $\dot{\mathrm{V}} \mathrm{O}_{2}$ recovery kinetics after submaximal exercise was accelerated by $20 \%$ due to improvement in microvascular $\mathrm{O}_{2}$ delivery-to-utilization matching once the skeletal muscle deoxygenation during submaximal exercise was attenuated and no changes were observed in CO kinetics (31).

Regarding $\mathrm{CO}$ recovery kinetics, results from the current study showed a statistically significant main effect of group on $\mathrm{A}$ of $\mathrm{CO}$ during recovery both in moderate and high intensity exercise bouts. The between-group effect size calculation revealed very large $(d=2.15)$ and large $(d=1.07)$ effect sizes for moderate and high loads, respectively. Considering that patients in CHF-COPD group reached lower values of $\mathrm{CO}$ at peak of exercise at high intensity $\left(\mathrm{CHF}=9.1 \pm 1.9\right.$ vs $\mathrm{CHF}-\mathrm{COPD}=7.5 \pm 2.5 \mathrm{~L} \cdot \mathrm{min}^{-1}$, Table $3, P<0.05$ ), it was expected that they would also exhibit lower values of $\mathrm{A}(\mathrm{CHF}=5.4 \pm 2.3$ vs $\mathrm{CHF}-\mathrm{COPD}=$ $3.4 \pm 1.4 \mathrm{~L} \cdot \mathrm{min}^{-1}$, Supplementary Table $\mathrm{S} 1, \mathrm{P}<0.05$ ). Myers et al. (9) analyzed the $\mathrm{CO}$ recovery kinetics by bioreactance after symptom-limited maximal exercise testing on treadmill and found that CHF patients with more severe disease, lower exercise capacity, and inefficient ventilation also demonstrated slower $\mathrm{CO}$ kinetics in recovery compared to controls.
Moreover, in our sample, CHF-COPD patients with abnormal MRT of $\dot{\mathrm{V}}_{2}$ during recovery after high-load exercise also demonstrated inefficient ventilation as evidenced by the strong positive relationship between $\dot{V}_{E} /$ $\dot{\mathrm{V}} \mathrm{CO}_{2}$ slope and MRT of $\dot{\mathrm{V}} \mathrm{O}_{2}$ during high CLET $(\mathrm{P}<0.05$, $r=0.71, R^{2}=50 \%$ ) (Figure 2). A heightened $\dot{V}_{E} / \dot{V} C_{2}$ slope is a hallmark of more severe $\mathrm{CHF}(32)$ and in the presence of COPD comorbidity, the expected alterations in lung function further worsen the ventilation-perfusion mismatch in the lungs and the ventilatory efficiency in CHF patients (3). In fact, the results of a recent study indicated that lower maximal exercise capacity in CHF-COPD patients was associated with greater ventilatory inefficiency, attenuated dynamic hyperinflation and lower peak $\mathrm{P}_{\mathrm{ET}} \mathrm{CO}_{2}$ compared to patients with COPD alone (33). Thus, our data suggested that the poorer ventilatory efficiency in CHF-COPD patients also reflected impaired $\mathrm{V}_{2}$ recovery kinetics particularly after high-CLET performance.

The lack of statistical significance in $\tau$ and MRT of HR, $\dot{\mathrm{V}} \mathrm{O}_{2}$, and $\mathrm{CO}$ during recovery showing that $\mathrm{CHF}$ and $\mathrm{CHF}-$ COPD groups were not differently affected by exercise intensity may be attributed to the small sample size. However, CHF-COPD $\tau$ and MRT means were greater than $\tau$ and MRT means in the CHF group, showing slowed recovery kinetics in CHF patients with comorbidity of COPD at both moderate and high loads (Supplementary Table S1). Besides, the between-group $\tau$ and MRT effect size calculation of $\mathrm{HR}, \dot{\mathrm{VO}}{ }_{2}$, and $\mathrm{CO}$ recovery kinetics showed that differences were more pronounced for the moderate load (effect size $>1.3$; Supplementary Table S1). In CHF, the delayed recovery from exercise may 
clinically contribute to the sensation of leg muscle fatigue reported by patients in activities of daily living (34). Following submaximal exercise, the $\mathrm{O}_{2}$ recovery kinetics seems to be limited more by $\mathrm{O}_{2}$ delivery than $\mathrm{O}_{2}$ utilization (35), suggesting that recovery from this type of exercise is limited by a reduced muscle blood flow in CHF patients (36). Recently, a prospective study assessed the role of central and peripheral impairments in the $\mathrm{O}_{2}$ transport pathway in limiting exercise tolerance in patients with COPD and CHF overlap compared to $\mathrm{FEV}_{1}$-matched COPD and LVEF-matched CHF patients. Besides the fact that patients with CHF-COPD had lower endurance exercise tolerance they also presented a greater impairment in leg muscle blood flow, but not arterial oxygenation, than CHF alone (37). Although in the present study peripheral hemodynamics was not assessed, we speculated that during recovery from exercise bouts, the impairment of muscle blood flow can also contribute to slow the $\mathrm{HR}, \dot{\mathrm{V}}_{2}$, and $\mathrm{CO}$ recovery kinetics particularly in CHF-COPD patients at higher loads. In addition to mechanisms that lead to reduced $\mathrm{O}_{2}$ delivery in $\mathrm{CHF}$ patients (heart failure per se, elevated vasoconstriction due to excessive sympathetic activity, higher plasma angiotensin levels, impaired nitric oxide-mediated vasodilation, and blunted redistribution of blood flow from the non-exercise tissues to exercising muscles (4)), the pulmonary mechanics abnormalities in COPD patients may entail negative cardiocirculatory effects (38). The excessive increase in abdominal, pleural, and alveolar pressures can reduce venous return, lowering right ventricle preload and elevating the afterload of both ventricles. Moreover, hyperinflation leads to capillary and pulmonary arteriole compression and may cause mechanical compression in the cardiac chambers decreasing their complacency (38).

\section{Clinical implications}

This is a novel cross-sectional study that aimed to investigate the influence of comorbidity of COPD in patients with CHF with reduced LVEF on recovery kinetics after moderate and high CLET. Our results added relevant information regarding recovery from constant load exercise assessment since the metabolic characteristics of recovery from submaximal exercise can clinically reflect prolonged dyspnea and leg effort experienced in activities of daily living of CHF (4) and very likely of CHF-COPD patients. Despite the lack of statistical significances, the effect size calculation - which is independent from sample sizes (27) - showed large/very large effect sizes in a considerable number of variables. Additionally, the assessment of recovery profile of CHF with comorbidity of COPD might also be useful to determine the effects of intervention that target the increase of skeletal muscle $\mathrm{O}_{2}$ delivery and/or reduction of $\mathrm{O}_{2}$ demand, such as physical training (31), non-invasive ventilation (39), and/or medicine prescription (e.g., sildenafil) (40).

\section{Limitations}

Certainly, the main limitation of our study was its small sample size. However, CHF and CHF-COPD patients were carefully examined by the joint force of cardiologists and pulmonologists and optimally treated before study initiation. Thus, we are confident that our results provide a good scenario to the alarming consequences of comorbidity of COPD in CHF patients. In addition, we acknowledge that the current results can only be applied in men, which might limit the external validity of the present study. Nevertheless, the homogeneity of our sample increased the internal validity of our results. We also recognize that the addition of a control group might have added comparative analysis to our results.

\section{Conclusion}

This is the first study to investigate the recovery kinetics after submaximal exercise in CHF patients with comorbidity of COPD. Although CHF and CHF-COPD groups were not affected differently by exercise intensity, the amplitude of $\mathrm{CO}$ was lower in CHF-COPD at both intensities, suggesting that the combination of CHF and COPD may further impair skeletal muscle $\mathrm{O}_{2}$ delivery compared to $\mathrm{CHF}$ alone. In addition, the poorer ventilatory efficiency in CHF-COPD patients also reflected impaired $\dot{\mathrm{V}}_{2}$ recovery kinetics particularly after high-intensity exercise performance. Given that patients with chronic cardiac and pulmonary diseases like CHF and COPD experience prolonged dyspnea and leg effort in activities of daily living, the recovery profile assessment after submaximal constant load exercise testing might be helpful to comprehend the metabolic characteristics that contribute to symptoms and exercise intolerance and to determine the effects of interventions such as exercise training, especially in patients with $\mathrm{CHF}$ and COPD overlap.

\section{Supplementary Material}

Click here to view [pdf].

\section{Acknowledgments}

The authors thank their colleagues from the Pulmonary Function and Clinical Exercise Physiology Division for kind collaboration. They also express their gratitude to all volunteers for their effort and cooperation throughout the study. Finally, we thank the Coordenação de Aperfeiçoamento de Pessoal de Nível Superior (CAPESPROEX) for financial support. 


\section{References}

1. Poole DC, Hirai DM, Copp SW, Musch TI. Muscle oxygen transport and utilization in heart failure: implications for exercise (in)tolerance. Am J Physiol Heart Circ Physiol 2012; 302: H1050-H1063, doi: 10.1152/ajpheart.00943. 2011.

2. O'Donnell DE, Laveneziana P, Webb K, Neder JA. Chronic obstructive pulmonary disease: clinical integrative physiology. Clin Chest Med 2014; 35: 51-69, doi: 10.1016/j.ccm. 2013.09.008.

3. Guazzi M, Myers J, Vicenzi M, Bensimhon D, Chase P, Pinkstaff $S$, et al. Cardiopulmonary exercise testing characteristics in heart failure patients with and without concomitant chronic obstructive pulmonary disease. Am Heart $J$ 2010; 160: 900-905, doi: 10.1016/j.ahj.2010.07.014.

4. Kemps HM, Schep G, Hoogsteen J, Thijssen EJ, De Vries $\mathrm{WR}$, Zonderland $\mathrm{ML}$, et al. Oxygen uptake kinetics in chronic heart failure: clinical and physiological aspects. Neth Heart $J$ 2009; 17: 238-244, doi: 10.1007/BF03086254.

5. Chiappa GR, Borghi-Silva A, Ferreira LF, Carrascosa C, Oliveira CC, Maia J, et al. Kinetics of muscle deoxygenation are accelerated at the onset of heavy-intensity exercise in patients with COPD: relationship to central cardiovascular dynamics. J Appl Physiol 2008; 104: 1341-1350, doi: 10.1152/ japplphysiol.01364.2007.

6. Daida H, Allison TG, Johnson BD, Squires RW, Gau GT. Further increase in oxygen uptake during early active recovery following maximal exercise in chronic heart failure. Chest 1996; 109: 47-51, doi: 10.1378/chest.109.1.47.

7. Belardinelli R, Barstow TJ, Nguyen $P$, Wasserman $K$. Skeletal muscle oxygenation and oxygen uptake kinetics following constant work rate exercise in chronic congestive heart failure. Am J Cardiol 1997 80: 1319-1324, doi: 10.1016/ S0002-9149(97)00672-3.

8. Scrutino D, Passantino A, Lagioia R, Napoli F, Ricci A, Rizzon P. Percent achieved of predicted peak exercise oxygen uptake and kinetics of recovery of oxygen uptake after exercise for risk stratification in chronic heart failure. Int J Cardiol 1998; 64: 117-124, doi: 10.1016/S0167-5273(98) 00019-9.

9. Myers JN, Guija P, Neelagaru S, Hsu L, Burkhoff L. Noninvasive measurement of cardiac performance in recovery from exercise in heart failure patients. Clinics 2011; 66: 649-656, doi: 10.1590/S1807-59322011000400021.

10. Fortin M, Turgeon PY, Nadreau É, Grégoire P, Maltais LG, Sénéchal $M$, et al. Prognostic value of oxygen kinetics during recovery from cardiopulmonary exercise testing in patients with chronic heart failure. Can J Cardiol 2015; 31: 1259-1265, doi: 10.1016/j.cjca.2015.02.015.

11. Vogiatzis I, Zakynthinos S, Georgiadou O, Golemati S, Pedotti A, Macklem PT, et al. Oxygen kinetics and debt during recovery from expiratory flow-limited exercise in healthy humans. Eur J Appl Physiol 2007; 99: 265-274, doi: 10.1007/s00421-006-0342-2.

12. Bellefleur $M$, Debeaumont D, Boutry $A$, Netchitailo $M$, Cuvelier A, Muir JF, et al. Early-phase recovery of cardiorespiratory measurements after maximal cardiopulmonary exercise testing in patients with chronic obstructive pulmonary disease. Pulm Med 2016; 2016: 9160781, doi: 10.1155/ 2016/9160781.
13. Baty F, van Gestel AJ, Kern L, Brutsche MH. Oxygen uptake recovery kinetics after the 6-minute walk test in patients with chronic obstructive pulmonary disease. Respiration 2016; 92: 371-379, doi: 10.1159/000452307.

14. Vestbo J, Hurd SS, Agustí AG, Jones PW, Vogelmeier C, Anzueto $A$, et al. Global strategy for the diagnosis, management, and prevention of chronic obstructive pulmonary disease: GOLD executive summary. Am J Respir Crit Care Med 2013; 187: 347-365, doi: 10.1164/rccm.2012 04-0596PP.

15. Balady GJ, Arena R, Sietsema K, Myers J, Coke L, Fletcher GF. Clinician's Guide to cardiopulmonary exercise testing in adults. a scientific statement from the American Heart Association. Circulation 2010; 122: 191-225, doi: 10.1161/ CIR.0b013e3181e52e69.

16. Asano RY, Sales MM, Vieira Browne RA, de Moraes JFVN, Sotero RDC, Arsa G, et al. High-intensity, but not moderate-intensity, exercise increases post-exercise rate of fat oxidation in type 2 diabetics. J Clin Transl Res 2016; 2: $55-62$.

17. Simões RP, Bonjorno JC Jr, Beltrame T, Catai AM, Arena R, Borghi-Silva A. Slower heart rate and oxygen consumption kinetic responses in the on- and off-transient during a discontinuous incremental exercise: effects of aging. Braz $J$ Phys Ther 2013; 17: 69-76, doi: 10.1590/S1413-3555201 2005000056

18. Miller MR, Hankinson J, Brusasco V, Burgos F, Casaburi R, Coates A, et al. ATS/ERS Task Force. Standardisation of spirometry. Eur Respir J 2005; 526: 319-338, doi: 10.1183/ 09031936.05 .00034805$.

19. Williams AJ. ABC of oxygen: assessing and interpreting arterial blood gases and acid-base balance. BMJ 1998; 317: 1213-1216, doi: 10.1136/bmj.317.7167.1213.

20. Lang RM, Badano LP, Tsang W, Adams DH, Agricola E, Buck $T$, et al. EAE/ASE recommendations for image acquisition and display using three-dimensional echocardiography. J Am Soc Echocardiogr 2012; 25: 3-46, doi: 10.1016/ j.echo.2011.11.010.

21. American Thoracic Society, American College of Chest Physicians. ATS/ACCP Statement on cardiopulmonary exercise testing. Am J Respir Crit Care Med 2003; 167: 211-277, doi: 10.1164/rccm.167.2.211.

22. Borg GA. Psychophysical bases of perceived exertion. Med Sci Sports Exerc 1982; 14: 377-381, doi: 10.1249/0000 5768-198205000-00012.

23. Baba $R$, Nagashima M, Goto M, Nagano $Y$, Yokota M, Tauchi N, et al. Oxygen uptake efficiency slope: a new index of cardiorespiratory functional reserve derived from the relation between oxygen uptake and minute ventilation during incremental exercise. J Am Coll Cardiol 1996; 28: 1567-1572, doi: 10.1016/S0735-1097(96)00412-3.

24. Castello-Simões V, Minatel V, Karsten M, Simões RP, Perseguini NM, Milan JC, et al. Circulatory and ventilatory power: characterization in patients with coronary artery disease. Arq Bras Cardiol 2015; 104: 476-485.

25. Borghi-Silva A, Labate V, Arena R, Bandera F, Generati G, Pellegrino $\mathrm{M}$, et al. Exercise ventilatory power in heart failure patients: functional phenotypes definition by combining cardiopulmonary exercise testing with stress echocardiography. 
Int J Cardiol 2014; 176: 1348-1349, doi: 10.1016/j.ijcard. 2014.07.268.

26. Charloux A, Lonsdorfer-Wolf E, Richard R, Lampert E, Oswald-Mammosser M, Mettauer B, et al. A new impedance cardiograph device for the non-invasive evaluation of cardiac output at rest and during exercise: comparison with the "direct" Fick method. Eur J Appl Physiol 2000; 82: 313320, doi: $10.1007 / \mathrm{s} 004210000226$.

27. Sullivan GM, Feinn R. Using effect size-or why the $p$ value is not enough. J Grad Med Educ 2012; 4: 279-282, doi: 10.4300/JGME-D-12-00156.1.

28. Munro BH. Statistical method for health care research. 4th ed. Philadelphia, PA: JB Lippincott; 2000.

29. Vasilopoulou MK, Vogiatzis I, Nasis I, Spetsioti S, Cherouveim E, Koskolou M, et al. On- and off-exercise kinetics of cardiac output in response to cycling and walking in COPD patients with GOLD Stages I-IV. Respir Physiol Neurobiol 2012; 181: 351-358, doi: 10.1016/j.resp.2012.03.014.

30. Kemps HM, de Vries WR, Schmikli SL, Zonderland ML, Hoogeveen AR, Thijssen EJ, et al. Assessment of the effects of physical training in patients with chronic heart failure: the utility of effort-independent exercise variables. Eur J Appl Physiol 2010; 108: 469-476, doi: 10.1007/ s00421-009-1230-3.

31. Spee RF, Niemeijer VM, Wijn PF, Doevendans PA, Kemps HM. Effects of high-intensity interval training on central haemodynamics and skeletal muscle oxygenation during exercise in patients with chronic heart failure. Eur J Prev Cardiol 2016; 23: 1943-1952, doi: 10.1177/2047487316 661615.

32. Arena R, Guazzi M, Myers J. Ventilatory abnormalities during exercise in heart failure: a mini review. Curr Resp Med Rev 2007; 3: 179-187, doi: 10.2174/157339807781 387517.

33. Arbex FF, Alencar MC, Souza A, Mazzuco A, Sperandio PA, Rocha $A$, et al. Exercise ventilation in COPD: influence of systolic heart failure. COPD 2016; 13: 693-699, doi: 10.1080/15412555.2016.1174985.

34. Picozzi NM, Clark AL, Lindsay KA, McCann GP, Hillis WS. Responses to constant work exercise in patients with chronic heart failure. Heart 1999; 82: 482-485, doi: 10.1136/ hrt.82.4.482.

35. Kemps HM, Schep G, Zonderland ML, Thijssen EJ, De Vries WR, Wessels B, et al. Are oxygen uptake kinetics in chronic heart failure limited by oxygen delivery or oxygen utilization? Intl J Cardiol 2010; 142: 138-144, doi: 10.1016/j.ijcard. 2008.12.088.

36. Kemps HM, Prompers JJ, Wessels B, De Vries WR, Zonderland $\mathrm{ML}$, Thijssen EJ, et al. Skeletal muscle metabolic recovery following submaximal exercise in chronic heart failure is limited more by $\mathrm{O}(2)$ delivery than $\mathrm{O}(2)$ utilization. Clin Sci 2009; 118: 203-210, doi: 10.1042/ CS20090220.

37. Oliveira MF, Arbex FF, Alencar MC, Souza A, Sperandio PA, Medeiros WM, et al. Heart failure impairs muscle blood flow and endurance exercise tolerance in COPD. COPD 2016; 13: 407-415, doi: 10.3109/15412555.2015.1117435.

38. Aliverti A, Macklem PT. How and why exercise is impaired in COPD. Respiration 2001; 68: 229-239, doi: 10.1159/000 050502.

39. Borghi-Silva A, Carrascosa C, Oliveira CC, Barroco AC, Berton DC, Vilaça D, et al. Effects of respiratory muscle unloading on leg muscle oxygenation and blood volume during high-intensity exercise in chronic heart failure. $\mathrm{Am} \mathrm{J}$ Physiol Heart Circ Physiol 2008; 294: H2465-H2472, doi: 10.1152/ajpheart.91520.2007.

40. Sperandio PA, Oliveira MF, Rodrigues MK, Berton DC, Treptow E, Nery LE, et al. Sildenafil improves microvascular O2 delivery-to-utilization matching and accelerates exercise O2 uptake kinetics in chronic heart failure. Am J Physiol Heart Circ Physiol 2012; 303: H1474-H1480, doi: 10.1152/ ajpheart.00435.2012. 